\title{
A comunicação ineficaz e a explosão da garrafa de álcool - observações de enfermagem
}

\author{
INEFFECTIVE COMMUNICATION AND ALCOHOL BOTTLE EXPLOSION: NURSING OBSERVATIONS \\ LA COMUNICACIÓN INEFICAZY LA EXPLOSIÓN DE LABOTELLADE ALCOHOL: \\ OBSERVACIONES DE ENFERMERIA
}

\author{
Maria Aparecida de Luca Nascimento ${ }^{1}$, Robson Bastos Lourenço ${ }^{2}$, Nebia Maria Almeida de \\ Figueiredo ${ }^{3}$, Joséte Luzia Leite ${ }^{4}$, Rubens Ghidini Junior ${ }^{5}$
}

\begin{abstract}
RESUMO
Estudo descritivo exploratório com abordagem quantitativa, cujo objetivo principal é apresentar o número de pacientes grandes queimados vítimas de explosão da garrafa plástica de álcool, que foram atendidos pela equipe de enfermagem, em um hospital de referência para este tratamento na cidade do Rio de Janeiro, nos anos de 2000 a 2002. Os dados foram extraídos do livro de atendimento de enfermagem do referido nosocômio. Os autores enfatizam que os meios de comunicação tratam o evento como "queimadura por álcool”, não como na realidade se apresenta: "queimadura por explosão", considerandose que a garrafa plástica de álcool é uma bomba em potencial, e suas vítimas assemelham-se aos queimados de guerra. Concluiu-se que muitos sofrimentos poderiam ser evitados por meio de uma comunicação efetiva, clara, e, acima de tudo, responsável.
\end{abstract}

\section{DESCRITORES}

Acidentes domésticos.

Queimaduras (enfermagem).

Etanol.

Meios de comunicação.

\begin{abstract}
The main goal of this descriptive exploratory study with a quantitative approach is to present the number of patients severely burned in alcohol plastic bottle explosions that have been cared for between 2000 and 2002 by the nursing staff of a Rio de Janeiro hospital that is a reference for the treatment of this kind of accident. The data was gathered from the nursing note book. The authors emphasize that the media refers to these victims as "burned by alcohol" rather than "burned by a bomb", since alcohol plastic bottles are potential bombs. The authors conclude that much suffering could be avoided through an effective, clear, and above all responsible communication.
\end{abstract}

\section{KEY WORDS}

Accidents, home.

Burns (nursing).

Ethanol.

Communications media.

\section{RESUMEN}

Estudio descriptivo exploratorio con abordaje cuantitativo, cuyo objetivo principal es presentar el número de pacientes gran quemados víctimas de explosión de una botella plástica de alcohol, que fueron atendidos por el equipo de enfermería, en un hospital de referencia para este tratamiento en la ciudad de Rio de Janeiro, entre los años del 2000 al 2002. Los datos fueron extraídos del libro de atenciones de enfermería del referido nosocomio. Los autores enfatizan que los medios de comunicación tratan el evento como "quemadura por alcohol" y no como se presenta en la realidad: "quemadura por explosión", considerándose que la botella plástica de alcohol es una bomba en potencia, y sus víctimas se asemejan a los quemados de guerra. Se concluyó que muchos sufrimientos podrían ser evitados por medio de una comu-nicación efectiva, clara y por encima de todo, responsable.

\section{DESCRIPTORES}

Accidentes domesticos. Quemaduras (enfermería). Etanol.

Medios de comunicación.
1 Orientadora Acadêmica Programa de Mestrado em Enfermagem da Escola de Enfermagem Alfredo Pinto da Universidade do Rio de Janeiro (UNIRIO) -

Doutora em Enfermagem. gemeas@centroin.com.br

2 Enfermeiro do Hospital

Municipal Miguel Couto -

RJ - Professor da Escola de Enfermagem Luiza de Marillac da Faculdade São Camilo e da Universidade Estácio de Sá - Mestre em Enfermagem

3 Professora Titular da EEAP da UNIRIO - Doutora em Enfermagem Pesquisadora CNPq

4 Professora Emérita da UNIRIO - Doutora em Enfermagem -

Pesquisadora CNPq

5 Acadêmico de Enfermagem da Universidade Estácio de Sá 
Maria Ap. de L. Nascimento Robson Bastos Lourenço Nebia Maria A. de Figueiredo Joséte Luzia Leite Rubens Ghidini Junior

\section{INTRODUÇÃO}

O cuidado de enfermagem prestado ao paciente grande queimado, vítima da explosão da garrafa plástica de álcool líquido, foi o fator desencadeante para a confecção deste estudo. $\mathrm{Na}$ nossa atuação como enfermeiros pudemos conviver com contexto dramático, composto pela dor e o sofrimento deste tipo de paciente. A complexidade deste tratamento, que por vezes tornase imprevisível, face às inúmeras intercorrências que podem acontecer durante a evolução do seu quadro clínico abrange também um grande desgaste, físico e mental Desta forma constatamos que

a queimadura extensa é um trauma catastrófico por ser uma agressão aflitiva ao paciente, nos seus aspectos psicológicos, de custos e de sofrimento para todos os envolvidos, seja o profissional, o paciente ou a sua família ${ }^{(1)}$.

Além dos aspectos supracitados, outros autores comentam e afirmam que

O paciente queimado apresenta características peculiares, em decorrência do sofrimento físico, da incerteza de sua recuperação e ainda pela presença constante do fantasma do desfiguramento ao longo de sua vida(2)

e observam que

os pacientes acometidos por grandes queimaduras são vítimas de três eventos potencialmente agressivos; tentativa de suicídio, tentativa de homicídio acidente(3).

Para efeito deste estudo, iremos nos deter no evento relacionado ao acidente, mais especificamente naquele que resulta da explosão da garrafa plástica de álcool líquido.Esta delimitação prende-se não só, ao fato da ocorrência supramencionada resultar em graves conseqüências, nas mais diversas esferas, que serão abordadas posteriormente, como também, pela possibilidade de, como todo acidente, poder ser evitado.

Desta forma, considerando que apesar deste assunto ser tratado com freqüência pela mídia, o número de casos continua a evoluir.

\section{OBJETIVOS}

1) Correlacionar a ocorrência da explosão da garrafa plástica de álcool líquido a um ruído na comunicação que trata deste evento.
2) Apresentar o número de pacientes grandes queimados vítimas de explosão da garrafa plástica de álcool que foram atendidas pela equipe de enfermagem em um hospital de referência para este tratamento na cidade do Rio de Janeiro, nos anos de 2000 a 2002.

\section{RELEVÂNCIA DO ESTUDO}

Ao considerarmos que a explosão de garrafa de álcool só é possível em sua forma líquida, cuja dinâmica será apresentada a seguir, é importante observar que com o advento do álcool sob a forma de gel, o evento que tratamos no presente estudo poderia ser evitado.

No entanto, a aceitação do álcool gel ainda encontra resistências em nosso meio, quer seja pela impossibilidade do seu uso em jato, fato que aumenta a segurança diante do seu uso perto de chamas, quer seja pelo seu preço, relativamente maior à sua apresentação na forma líquida.

Considerando por um lado, a importância de evitar-se os acidentes decorrentes da explosão de garrafa de álcool, e por outro, o avanço tecnológico que subsidiou a criação do álcool em sua forma gel (coloidal), algumas medidas de cunho representativo foram tomadas.

Entre elas, destacamos a Resolução de Diretoria Colegiada $(\mathrm{RDC}) \mathrm{n}^{\mathrm{o}} 46$ de 20 de fevereiro de 2002, publicada em D.O.U. de 21 de fevereiro do mesmo ano (Anexo I), que em seu Art $2^{\circ}$ inciso III restringe a venda do álcool às instituições, proibindo-a ao público, sendo que a adoção desta medida, entre outras, ainda segundo a própria resolução contida no seu "caput", é relativa à prevenção dos "riscos oferecidos à saúde pública decorrentes de acidentes por queimaduras e ingestão."

Com relação ao documento citado, cumpre lembrar que as empresas envolvidas na comercialização do álcool líquido envasado em vasilhame plástico entraram com um recurso apelando para a sua revogação.

Outra medida, datada de agosto de 2003, veiculada pela Associação Brasileira de Queimaduras, diz respeito à notificação, por parte de seus associados, da ocorrência de atendimento de pacientes vítimas de explosão de garrafa de plástico de álcool líquido, no sentido de estabelecer um controle epidemiológico deste acidente, por parte da ANVISA(Agência Nacional de Vigilância Sanitária). 
A medida supracitada tem por objetivo demonstrar quantitativamente qual é o resultado da venda livre do álcool envasado em vasilhame plástico, apontando através destes números os prejuízos que são causados à população.

\section{A GARRAFA PLÁSTICA DE ÁLCOOL - UMA BOMBA EM POTENCIAL (Explicando a dinâmica explosiva)}

Considerando que o objetivo $\mathrm{n}^{\circ} 1$ deste estudo diz respeito ao ruído na comunicação sobre o acidente com o uso da garrafa plástica de álcool líquido, passamos a descrever a dinâmica explosiva deste vasilhame, para posteriormente correlacionarmos esta dinâmica a seguinte comunicação:

As manifestações patológicas apresentadas por um organismo vivo que foi submetido à uma explosão, decorre do impacto da onda de choque, mecanismo inicialmente descrito por Ambroise Paré no século XVI. Essas manifestações são denominadas de "blust"(4).

Ainda segundo o mesmo autor, essas patologias inicialmente eram conhecidas dos profissionais que atuavam em conflito de guerra, mas hoje, em virtude da sua ocorrência são conhecidos de todos os profissionais que trabalham em emergência. As ondas de choque derivam de explosões ligadas a fagulhas ou incêndios".

A partir de uma explosão, as lesões dela decorrente são de três tipos:

1 - "Blust" primário - Ação direta da onda de choque sobre o corpo.

2 - "Blust"secundário - Lesões resultantes de projéteis que atingem o organismo em decorrência da explosão.

3 - "Blust" terciário - traumatismo cinético da própria vítima projetada contra um corpo ou superfície.

Considerando o objeto deste estudo, qual seja, o risco que a explosão da garrafa plástica de álcool líquido representa para a população, aliado à falta de ênfase veiculada pelos canais de comunicação, com relação ao seu mecanismo explosivo, podemos observar que a explosão da garrafa de álcool acarreta lesões decorrentes do "blust" primário, sendo essas conseqüências tão mais graves quanto mais próximo da explosão se encontrar o paciente, que na maioria das vezes está segurando a garrafa de plástico, que ao ser comprimida (possibilidade advinda da sua plasticidade), em direção à chama, num mecanismo de equiparação de pressão, tende a sugala para o seu interior, provocando a explosão.
Neste ponto vale ressaltar, que a distância entre a vítima e a garrafa plástica de álcool líquido não interfere no perigo que ela representa, pois se o jato for ininterrupto, a 1 ou 10 metros de distância, haverá a explosão.

Porém, neste ponto, cumpre citar o atendimento a uma dona de casa, vítima de explosão da garrafa plástica de álcool líquido, que ao borrifá-lo sobre uma mesa de fórmica para limpá-la, provocou o acidente que lhe causou sérias lesões. A referida mesa estava acerca de 3 metros do fogão em uma cozinha fechada. Ocorre que o álcool, sob a forma de aerosol, ficou no ar, formando uma ponte entre a chama e a garrafa, promovendo a explosão ao sugar o fogo para dentro dela. Neste caso, mesmo não sendo direcionado diretamente à chama, o acidente aconteceu.

Outro ponto a ser observado é a relação existente entre a quantidade de álcool líquido existente dentro da garrafa e o perigo que ela representa. Por analogia seria como comparar o potencial explosivo de uma bomba, de acordo com a quantidade de pólvora contida em seu interior.

Desse modo, entender tão somente o paciente grande queimado como uma vítima de acidente tendo como agente causal, o álcool, não é o suficiente. Há que se entender também, que uma vez submetido à onda de choque, uma das principais agressões à qual ele é submetido, é a ruptura alveolar que, conseqüentemente, induz à formação de edema alveolar, levando-o a um grave comprometimento respiratório.

Por um mecanismo de associação aos efeitos descritos podemos inferir que além desta agressão, outras decorrem pela explosão da garrafa plástica de álcool, pois há também a propagação da onda de choque em meio liquido ${ }^{(4)}$.

Desta forma, as partes do corpo, tais como; o encéfalo, fígado, baço, rim, olho, testículo, que possuem líquido na sua constituição, ao serem afetados pela explosão, trazem ao paciente grande sofrimento, decorrente dos seus acometimentos, físico e funcional.

Ao considerarmos as estruturas das quais são compostos o corpo humano, podemos observar que as agressões decorrentes da propagação da onda de choque também afetam o meio sólido, representado pelo esqueleto, e propagam-se também no ar e meio ambiente, afetando ouvidos, pulmões e vísceras ocas.

Neste ponto é importante citar o comportamento do paciente grande queimado quando chega à
A comunicação ineficaz e a explosão da garrafa de álcool observações de enfermagem 
Maria Ap. de L. Nascimento Robson Bastos Lourenço Nebia Maria A. de Figueiredo Joséte Luzia Leite Rubens Ghidini Junior

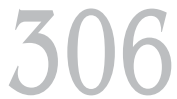

Rev Esc Enferm USP 2005; 39(3):303-9. emergência dos hospitais: entre os vários sinais que podem ser observados pela equipe que o atende, podemos citar a demora para responder às solicitações, o que pode ser creditado à uma surdez provocada pela onda de choque no ar e no meio ambiente ${ }^{(5)}$.

A compreensão da dinâmica explosiva, supracitada em parágrafo anterior, nos permite, como enfermeiros, dimensionar a gravidade de que se reveste o evento da explosão de uma garrafa plástica de álcool, através dos seus efeitos no corpo humano.

Sendo assim, é possível, através do conhecimento da seqüência acima descrita, visualizar o corpo do paciente grande queimado quando chega às nossas mãos para ser cuidado, como uma vítima de um campo de guerra.

Um dos principais sinais observados durante a assistência de enfermagem ao paciente grande queimado, vítima de explosão da garrafa plástica de álcool líquido, é o seu estado de choque, expondo a sua vulnerabilidade emocional, causada pela surpresa do acidente. Além deste sinal, de acordo com a nossa prática cotidiana, outro se instala, que é a presença de sangue na ponta da sonda de aspiração traqueal, procedimento ao qual este tipo de paciente, normalmente, é submetido, em virtude da sua insuficiência respi- ratória, já citada anteriormente, causada não só, pela aspiração de vapor aquecido, como também, pela onda de choque decorrente do "blust" primário.

\section{OS NÚMEROS QUE DENUNCIAM UMA REALIDADE}

Tendo em vista o objetivo $\mathrm{n}^{\mathrm{o}} 2$ deste estudo, passamos a apresentar o número de ocorrência de atendimento de enfermagem a pacientes grande queimados por explosão de garrafa de álcool, em um centro de referência para este tipo de tratamento, situado no Rio de Janeiro, no período mencionado, como uma forma de diagnosticar, simplificadamente, o risco de que se reveste utilização deste líquido, envasado neste tipo de vasilhame. Por oportuno, vale ressaltar que os dados foram extraídos do livro de ocorrências de enfermagem do Centro de Tratamento de Queimados do Hospital Municipal Souza Aguiar (HMSA). O HMSA é um hospital de emergência e de grande porte, situado no centro da cidade do Rio de Janeiro, que atende a uma grande demanda da população, tanto da sua área programática, quanto de regiões adjacentes. Sendo assim, considerando a demanda da população atendida, elegemos o HMSA para extrair os dados abaixo, por considerá-los representativos para este estudo.

Quadro 1 - Número de ocorrências de explosão de garrafa plástica de álcool, distribuídas de acordo com o sexo, S.C.Q. (superfície corporal queimada) e idade de suas vítimas. (Rio de Janeiro, jan./2000 a dez./2002)

\begin{tabular}{|c|c|c|c|c|c|c|c|c|c|c|c|c|}
\hline \multirow{3}{*}{ Ocorrências } & \multicolumn{3}{|c|}{ Ano } & \multicolumn{2}{|c|}{ Sexo } & \multicolumn{4}{|c|}{ S.C.Q. } & \multicolumn{3}{|c|}{ Idade } \\
\hline & 2000 & 2001 & 2002 & M & $\mathrm{F}$ & $+20 \%$ & $+40 \%$ & $+50 \%$ & $+60 \%$ & -20 & +20 & +50 \\
\hline & 14 & 27 & 35 & 45 & 31 & 53 & 9 & 9 & 5 & 10 & 50 & 16 \\
\hline Total & \multicolumn{3}{|c|}{76} & \multicolumn{2}{|c|}{76} & \multicolumn{4}{|c|}{76} & \multicolumn{3}{|c|}{76} \\
\hline
\end{tabular}

Fonte: Livro de ocorrências de enfermagem da Unidade de Tratamento de Queimados do Hospital Municipal Souza Aguiar - RJ

Quadro 2 - Número de óbitos ocorridos em conseqüência de explosão de garrafa plástica de álcool líquido. (Rio de Janeiro, jan./2000 a dez./2002)

\begin{tabular}{|c|c|}
\hline ANO & $\mathbf{N}^{\mathbf{o}}$ DE ÓBITOS \\
\hline 2000 & 5 \\
2001 & 10 \\
2002 & 3 \\
\hline TOTAL & 18 \\
\hline
\end{tabular}

Fonte: Livro de ocorrências de enfermagem da Unidade de Tratamento de Queimados do Hospital Municipal Souza Aguiar - RJ

\section{APRESENTAÇÃOE ANÁLISE DOS RESULTADOS}

De acordo com os dados obtidos, pudemos constatar que o índice de ocorrências de queimaduras por explosão de garrafa de álcool totalizou 14 casos no ano de 2000, 27 em 2001, e 35 em 2002, mostrando a tendência evolutiva do número de acidentes por explosão de garrafa plástica de álcool líquido, sendo que de um total de 76 pacientes, conforme o Quadro 1 demonstra, 18 (23\%) morreram (Quadro 2). 
Com relação à incidência do acidente por explosão de garrafa plástica de álcool, considerando o sexo das vítimas, pudemos observar que os números são praticamente os mesmos, o que pode ser creditado ao fato da referida substância não ser manuseada somente pelas mulheres. Essa análise, sendo conseqüência da observação dos acidentes, em sua maioria, referirem-se a acidentes domésticos, leva-nos a inferir que esses números podem estar relacionados aos churrascos que são produzidos por ambos os sexos nos finais de semana, quando o álcool líquido é utilizado como combustível para as chamas.

Considerando que a referência do álcool como agente causal dos acidentes que acometem a população, normalmente dão a idéia errônea de que a queimadura seria causada pelo seu contato em combustão com a pele, e não à idéia do que realmente representa, ou seja; uma bomba explodindo, observa-se este efeito a partir da superfície corporal queimada (S.C.Q.) de suas vítimas, classificado-as como grande queimadas: "O paciente é considerado grande queimado a partir de um percentual acima de 20 , de toda a superfície do seu corpo"(2).

Deste modo, dos 76 pacientes que compuseram a população-alvo, 53 estavam com acometimento acima de $20 \%$ de S.C.Q., 9 estavam acima de $40 \%$ de S.C.Q., 9 estavam acima de $50 \%$, e 5 com queimaduras acometendo cerca de $60 \%$ de S. C. Q.

Dos 76 pacientes, a maior parte, 50 deles (65\%), encontravam-se na faixa etária, considerada socialmente produtiva, entre 20 e 49 anos.

Neste ponto, vale enfatizar que a gravidade das lesões, mensurada normalmente pela unidade de superfície corporal queimada (S.C.Q.), diz respeito ao contato das chamas com o corpo. Na prática cotidiana de cuidar do paciente queimado, observa-se também, que tão importante para o diagnóstico e avaliação é a profundidade destas lesões, classificadas em lesões de primeiro, segundo e terceiro graus.

Outro fator importante a ser observado no diagnóstico do paciente grande queimado, é sua área acometida pela lesão, que será tão mais grave, à medida que comprometer determinadas "áreas nobres". Estas áreas são assim consideradas de acordo com o risco da morbi- mortalidade a que expuser o paciente: face, mãos, pés, genitália, região perianal, tórax ${ }^{(2)}$.

Sendo assim, a gravidade das queimaduras pode ser creditada, não só à mortalidade dos paci- entes por elas acometidos, mas também pela morbidade observada a partir da sua interferência nas funções das partes do corpo acima descrita e que, muitas vezes, incapacitam as suas vítimas para o trabalho e/ou para o convívio social.

As perdas; da vida, da função motora, do convívio humano, foram mencionadas e fazem parte de bibliografias consultadas, no entanto, observase que nelas, não há qualquer menção relacionada à gravidade das lesões provocadas por explosões da garrafa plástica de álcool líquido, que além das queimaduras no corpo da vítima, que foram mencionadas, causam danos em sua estrutura interna, a partir da onda de choque, mecanismo apresentado anteriormente.

\section{O EVENTO DAEXPLOSÃO DA GARRAFA PLÁSTICA DE ÁLCOOL LÍQUIDO VEICULADA PELA MÍDIA \\ (A informação e o ruído da comunicação)}

Ao correlacionarmos as citações relativas à dinâmica explosiva da garrafa plástica de álcool líquido, à reportagem abaixo, citada na íntegra, podemos perceber que em nenhum momento houve a comparação deste vasilhame à uma bomba. Porém, elementos da informação foram mencionados, relativos, inclusive ao perigo da embalagem plástica, mas sem explicar como e porquê. Eis a reportagem:

\section{GRUPO GANHA NA JUSTIÇA DIREITO DE COMERCIALIZAR ÁLCOOL LÍQUIDO}

\section{Reportagem veiculada pelo Jornal Nacional da Rede Globo em 11/02/2004}

A Agência Nacional de Vigilância Sanitária quer impedir que fabricantes continuem vendendo álcool líquido ${ }^{(6)}$.

Tem gente que prefere álcool líquido

Porque é mais fácil de ser usado, diz uma senhora.

Tem secagem rápida. O gel não tem, avisa outra.

Ângela gosta mais de gel. É mais econômico, por causa da gotinha, você pinga um pouquinho e ele não derrama, ensina ela.

A filha da empregada doméstica Vera Lucia de Barros se queimou com álcool líquido, perto da churrasqueira.
A comunicação ineficaz e a explosão da garrafa de álcool observações de enfermagem 
Maria Ap. de L. Nascimento Robson Bastos Lourenço Nebia Maria A. de Figueiredo Joséte Luzia Leite Rubens Ghidini Junior
Ela jogou e caiu no rostinho dela. Esse negócio de queimadura a gente não sabia o que fazia, só saímos correndo pra levar ela pro hospital, conta.

Num hospital público do Rio, considerado de referência nacional no tratamento de queimados, de cada dez pessoas que chegam, à emergência, três foram vítimas de algum acidente com álcool líquido.

No período em que a venda foi proibida, notou-se uma mudança. O número de pacientes com álcool líquido caiu pela metade.

No ano passado, foram 471 casos. Em 2001, um ano antes da proibição da venda, esse número chegou a 944 .

É a segunda vez que o comerciante Sebastião dos Santos se queima dentro de casa. Ele traz marcas da infância.

Naquela época, eu estava com 10 para 11 anos, lembra.

Médicos defendem restrições imediatas à venda do álcool líquido.

Ele não pode ser comercializado em supermercados, em embalagens plásticas, porque ai é o grande risco, é o grande perigo do uso indevido do álcool. Essa comercialização do álcool líquido tem que ser modificado, alerta Everardo Abramo, presidente da Sociedade Brasileira de Cirurgia Plástica do Rio de Janeiro.

\section{CONCLUSÃO}

Ao observarmos o quantitativo de pacientes vítimas da explosão da garrafa plástica de álcool líquido citada na reportagem acima, assim como aquela apresentada neste estudo, podemos perceber a seriedade do tema tratado, e o ruído que existente nas informações veiculadas pelos canais de comunicação, em especial a televisão, que segundo Rossi foi apontada como sendo aquele que mais informação veicula a respeito de acidentes que levam ás queimaduras. Porém, podemos observar em várias outras reportagens, inclusive em revistas técnicas, que a garrafa plástica de álcool não é tratada como uma bomba em potencial. Sendo assim, inferimos que este ruído na comunicação pode ser o responsável pelo fato da comunidade não atentar para o perigo que representa ter uma bomba junto a si, prestes a explodir, desde que manuseada sem o respectivo conhecimento de sua periculosidade. Outro fato a ser considerado, é a familiaridade que a comunidade tem com a garrafa plástica de álcool líquido, diferentemente daquela que tem com uma bomba, que mesmo que estivesse à venda nas prateleiras dos supermercados, ninguém gostaria de ter em casa. Sendo assim, conclui-se que a partir de uma comunicação efetiva, clara, e acima de tudo, responsável, da qual constassem os elementos apresentados neste estudo, muita dor e sofrimento causado pela explosão da garrafa plástica de álcool líquido, poderiam ser evitados, pois nesta guerra que se constitui o comércio, como em todas as outras guerras, os motivos que as deflagram, normalmente, são desconhecidos de suas vítimas.

\section{REFERÊNCIAS}

(1) Artz CP, Moncrief JA, Pruitt Jr A. Queimaduras. Rio de Janeiro: Interamericana; 1988.

(2) Gomes DR, Serra MC, Luiz Jr M. Condutas atuais em queimaduras. Rio de Janeiro: Revinter; 2001.

(3) Nascimento MAL. O estudante de enfermagem frente ao banho terapêutico do grande queimado. Rev Bras Enferm 1986; 39(2/3):51-4.

(4) Julien H. Lesões decorrentes da onda de choque conseqüente à explosão. Rev Bras Emerg Hosp Med Desastres 1995; 2(1):26-8.

(5) Lourenço RB. Diagnóstico simplificado sobre os riscos do uso da garrafa plástica de álcool líquido pela população - Reflexão e providências para uma enfermagem preventiva. [dissertação]. Rio de Janeiro (RJ): Escola de Enfermagem Alfredo Pinto UNIRIO; 2004. p. 13.
(6) Grupo ganha na justiça direito de comercializar álcool líquido. J Nac [periódico online] Rio de Janeiro, 11 fev. 2004. Disponível em: http:// jornalnacional.globo.com/Jornalismo/JN/ 0,,AA781565-3586,00.html (12 fev. 2004)

(7) Rossi LA, Ferreira E, Costa ECFB, Bergamasco EC, Camargo C. Prevenção de queimaduras: percepções de pacientes e de seus familiares Rev Lat Am Enferm 2003; 11(1)36-42. 


\section{ANEXO I - RESOLUÇÃO}

\section{RESOLUÇÃO - RDC No 46 de 20 de fevereiro de 2002 - DOU de 21/2/2002}

A diretoria Colegiada de Agência Nacional de Vigilância Sanitária no uso da atribuição que lhe confere o art. 11, inciso IV, do regulamento da ANVISA, aprovado pelo Decreto ${ }^{\circ}{ }^{\circ} 3.029$, de 16 de Abril de 1999, c/ o $\$ 1^{\circ}$ do Art. 111 do Regimento Interno aprovado pela portaria ${ }^{\circ} 593$, de 25 de agosto de 2000 , em seu anexo II, em reunião realizada em 20 de fevereiro de 2002,

Considerando a legislação sanitária, em especial a Lei 6360, de 23 de setembro de 1976 eo Decreto $\mathrm{n}^{0} 79094$, de 5 de janeiro de 1977 ,

Considerando as Normas Brasileiras Registradas da Associação Brasileira de Normas Técnicas NBR n. 5991/97 e suas atualizações,

Considerando os riscos oferecidos à saúde pública decorrente de acidentes por queimadura e ingestão, principalmente em crianças, em virtude da forma física para o álcool etílico, atualmente sem restrições na forma líquida, incompatível com as recomendações e precauções sanitárias,

Adota a seguinte Resolução, e eu, Diretor-Presidente, determino a sua publicação:

Art. $1^{\circ}$ Aprovar o Regulamento Técnico para o álcool etílico hidratado em todas as graduações e álcool etílico anidro, comercializado por atacadistas e varejistas.

Art. $2^{\circ} \mathrm{A}$ industrialização, exposição à venda ou entrega ao consumo, em todas as suas fases, do álcool etílico hidratado em todas as graduações e do álcool etílico anidro estão sujeitas às seguintes concentrações, condições e finalidades como substância ou produto.

I - o álcool etílico comercializado com as graduações acima de $54^{\circ} \mathrm{GL}$ (cinqüenta e quatro graus Gay Lussac) à temperatura de $20^{\circ} \mathrm{C}$ (vinte graus Celsius) deverá ser comercializado unicamente em solução coloidal na forma gel desnaturada e no volume máximo de 500g (quinhentos gramas), em embalagens resistentes ao impacto. Para formulações que apresentem valores superiores ou iguais a $68 \% \mathrm{p} / \mathrm{p}$ (sessenta e oito porcento, peso por peso).

II - os produtos formulados à base de álcool etílico hidratado comercializado com graduações abaixo ou igual a $54^{\circ} \mathrm{GL}$ (cinqüenta e quatro graus Gay Lussac) à temperatura de $20^{\circ} \mathrm{C}$ ( vinte graus Celsius) deverão conter desnaturante de forma a impedir seu uso indevido.

III - o álcool etílico industrial e o álcool destinado a testes laboratoriais e à investigação científica, hidratado ou anidro, quando comercializado em volume menor ou igual a 2001 (duzentos litros) deverá conter tampa com lacre de inviolabilidade e, no rótulo, além das frases constantes do anexo I,deverão constar nas advertências gerais a seguinte instrução:PERIGO:PRODUTO EXCLUSIVAMNETE DE USO INSTITUCIONAL.

IV- o álcool puro ou diluído somente poderá ser comercializado nos locais de dispensão, nos termos da lei 5991 de 17 de dezembro de 1973, quando a finalidade de uso não se enquadrar nas condições técnicas de desnaturamento ou forma de gel, nos termos desta Resolução, até o volume máximo de 50 $\mathrm{ml}$ ( cinqüenta mililitros).

$\$ 10$ Para os fins do disposto neste artigo, excluem-se aqueles com finalidade exclusivamente industrial, com volumes superiores a 200L (duzentos litros), assim como para bebidas alcoólicas.

\$20 Para fins desta resolução define-se como álcool desnaturado o álcool adicionado de uma ou mais substâncias identificadas de sabor ou odor repugnante, afim de impedir seu uso em bebidas, alimentos e produtos farmacêuticos e não possuir efeito toxicológico que possa causar agravo á saúde.

Art $3^{\circ}$-Os dizeres de rotulagem dos produtos mencionados no artigo 2,Incisos I,III e IV, deverão atender ao disposto no Anexo I deste regulamento.

Art. $4^{\circ}$ - È vedada a utilização na embalagem, rotulagem e propaganda dos produtos de que trata esta resolução, de designações, nomes geográficos,símbolos,figuras,desenhos ou quaisquer outras indicações que induzam sua utilização indevida e atraiam crianças.

Art. $5^{\circ}$-As situações em desacordo com o disposto nesta Resolução e seus Anexos , constituem infração sanitária, sujeitando o infrator ás penalidades na Lei nº437 de agosto de 1977. e demais normas cabíveis.

Art. $6^{\circ}$-Fica concedido o prazo de 180 (cento e oitenta) dias, para que os fabricantes dos produtos se adeqüem aos dispositivos da presente Resolução.

Art. $7^{\circ}$-Esta norma revoga as demais disposições em contrário e entrará em vigor na data de sua publicação.

Gonzalo Vecina Neto

A comunicação ineficaz e a explosão da garrafa de álcool observações de enfermagem
Correspondência: Joséte Luzia Leite Rua Afonso Cavalcanti, 275 - Cidade Nova Rio de Janeiro CEP - 20211-110 -RJ 